TÜRÜK

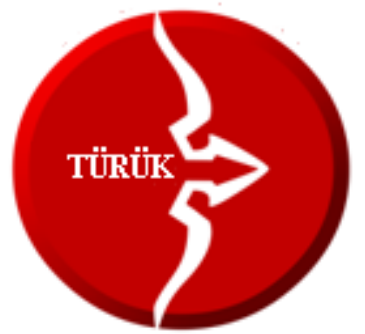

Uluslararası Dil, Edebiyat

ve Halkbilimi Araştırmalan Dergisi

2014 Yll:2, Sayı:4

Sayfa: 1-36

ISSN: $2147-8872$

\title{
ÜSKÜP TÜRK AĞZINDA KİP EKLERİ
}

Oktay Ahmed*

\section{Özet}

Bu çalışmada, Üsküp (Makedonya Cumhuriyeti) Türk ağzındaki bildirme ve dilek kip ekleri ve varyantları ele alınmıştır. Üsküp ağzında şimdiki zaman kipinin geniş zaman kipine yeğlendiği, geniş zaman kipinin çok nadir kullanıldığı, istek ve emir kiplerinin birbirine karıştığı, gereklilik kipinin ise morfolojik olarak değil de leksik unsurlarla yapıldığ örnekleriyle verilmiştir. Makedonya ve Rumeli'nin diğer Türk ağızlarında da olduğu gibi, Üsküp ağzında da eklerin varyantlarında eksiklik vardır veya varyantların kullanımında farklılıklar göze çarpmaktadır. Literatürde Üsküp ağzı hakkında çok az malzeme vardır. Bunlar da kısmen doğru tespitlerdir ve genelde Rumeli ağıları kapsamında genellemeler çerçevesindedir. Çok ilginçtir ki, Türk Dili ve Edebiyatı Bölümü Makedonya'nın başkenti Üsküp'te (Skopje) bulunmasına rağmen, eriyip elden gitmesinler diye, şimdiye kadar hep Üsküp dişındaki ağılar ayrıntılı bir şekilde incelenmiştir. Bugüne kadar Üsküp Türk ağzıyla ilgili belli başlı hiçbir çalışma bulunmamaktadır. Çeşitli diğer çalışmalarda Üsküp ağzının bazı özelliklerine değinilse de bunlar bu ağzın derli toplu özelliklerini görmek için yetersiz veya başkaları tarafindan aktarmalı bilgilerdir.

Anahtar kelimeler: Üsküp Türk ağzı, Makedonya ağızları, kip ekleri, morfoloji.

\section{MODAL SUFFIXES IN THE TURKISH DIALECT OF SKOPJE}

\begin{abstract}
This paper discusses the temporal and modal suffixes and their variants in the Turkish dialect of Skopje (Republic of Macedonia). The preference of present tense over the aorist, the rare use of aorist, the mixed usage of optative and imperative mood, the build of necessitative mood not with morphological, but with lexical elements in the Skopje dialect are given with their relevant examples in this paper. In the Skopje dialect, as well
\end{abstract}

- Prof. Dr., Üsküp “Aziz Kiril ve Metodiy” Üniversitesi, "Blaje Koneski” Filoloji Fakültesi, Türk Dili ve Edebiyat1 Bölümü (Makedonya), oktayahmed@gmail.com 
as in the other Turkish dialects of Macedonia and Rumelia, the suffixes have fewer variants and the differences of the variants usages draw the attention. In the literature, there is almost nothing about this dialect. These findings are partly accurate and mainly discussed in the broader Rumelian dialects. It's very interesting that even there is a Department of Turkish Language and Literature in Skopje, the capital of Macedonia, there are plenty of detailed works of other dialects outside of Skopje, just because of fear of their disappearing. Nowadays, there is simply no major work at all about the Turkish dialect of Skopje. Even some characteristics of the dialect of Skopje could be found in various studies, these are not enough to catch the broader picture about the wide characteristics of this dialect, or mainly they are indirect information.

Keywords: Skopje Turkish dialect, Macedonian dialects, tense suffixes, modal suffixes, morphology.

\section{Giriş}

Ünlü Makedon aydını Görgi Pulevski, daha XIX. yüzyılda Belgrad'da yayımladığı iki çalışmasında, Makedonya Türk ağızları üzerine dolaylı bir şekilde bilgi vermektedir. Pulevski'nin 1873 basımlı “Dört Dilli Sözlük”ü (Пулевски, 1873), hemen ardından da 1875 yılında bastığı “Üç Dilli Sözlük”ünün (Пуљевски, 1875) Kiril harfleriyle yazılmış olduğu Türkçe kısımlarında, bu ağızlar hakkında yeterince bilgi edinilebilmektedir (Ahmed, 2012b). $\mathrm{Bu}$ iki çalışmayı Türkoloji dünyasına ilk tanıtan "Rumeli Ağızları Tarihinin İki Kaynağı Üzerine” adlı çalışmasıyla Hazai olmuştur (Hazai, 1964).

Makedonya Türk ağızlarıyla ilgili ilk çalışmalar, Rumeli Türk ağızları çerçevesinde, XX. yüzyılın başlarında yapılmıştır (Kúnos, 1918; Kowalski, 1919; Kowalski, 1926). Diğer ufak tefek çalışmalardan sonra, ancak Gyula Németh 1956 y1lında "Bulgaristan Türk Ağızlarının Sinıflandırılması Üzerine” adlı Sofya'da yayımladığı çalışmasında (Németh, 1956), Balkan Türk ağızlarını, dolayısıyla kısmen Makedonya Türk ağılarını da kapsamış ve sınıflandırmıştır. Németh’e göre, Makedonya Türk ağızları, "Batı Rumeli Türk Ağzı"na girer (Németh, 1983: 120).

Makedonya Türk ağızlarıyla daha derli toplu çalışmalar II. Dünya Savaşı'ndan sonra bazı yabancılar ve Makedonyalı dilciler tarafından yapılmıştır, ancak 1965 yılında "Sesler" dergisinin yayın hayatına başlaması, hele hele Üsküp "Aziz Kiril ve Metodiy” Üniversitesi Filoloji Fakültesi dâhilinde 1976 yılında Türk Dili ve Edebiyatı Bölümü’nün kurulmasıyla, bu çalışmalar daha sistematik bir şekilde yapılmaya başlamıştır. Bu Bölüm’de şimdiye kadar birçok yüksek lisans ve doktora tezi yapılmıştır ve başarıyla savunulmuştur.

2002 yılında yapılan son sayımlara göre, Makedonya Cumhuriyeti'nin toplam nüfusu 2.022.547'dir. Türklerin sayıs1 ise 77.959'dur (toplam nüfusun \%3,9'u). Üsküp'ün toplam nüfusu 506.926'dır. Bunlardan, kendini Türk olarak ifade edenlerin sayısı ise 8595'tir ( \%1,7). Diğer sözlerle, Makedonya Türklerinin \%11'i Üsküp'te yaşamaktadır (Државен завод за статистика, 2005: 34). 
Literatürde Üsküp ağzı hakkında çok az malzeme vardır. Bunlar da kısmen doğru tespitlerdir ve genelde Rumeli ağıları kapsamında genellemeler çerçevesindedir.

Çok ilginçtir ki, Türk Dili ve Edebiyatı Bölümü Makedonya'nın başkenti Üsküp’te (Skopje) bulunmasına rağmen, eriyip elden gitmesinler diye, şimdiye kadar hep Üsküp dışındaki ağızlar ayrıntılı bir şekilde incelenmiştir. Bugüne kadar Üsküp Türk ağzıyla ilgili belli başlı hiçbir çalışma bulunmamaktadır. Çeşitli diğer çalışmalarda Üsküp ağzının bazı özelliklerine değinilse de (Ahmed, 2012a; Ahmed, 2014 gibi), bunlar bu ağzın derli toplu özelliklerini görmek için yetersiz veya başkaları tarafindan aktarmalı bilgilerdir.

Üsküp ağzında da, diğer Makedonya Türk ağızlarında olduğu gibi, eklerin varyantlarında eksiklik görülmektedir (Ahmed, 2007). Bunun nedeni, genel bir izlenim olarak, ünlü uyumlarının bulunmayışından dolayıdır.

\section{Üsküp Türk Ağzında Kip Ekleri}

Genelde, dünya dilbilim çalışmalarında Türkçede kip ekleri adı altında ele alınan kavramlar iki grupta incelenir:

- $\quad$ bildirme (temporal, zaman) ekleri;

- $\quad$ dilek (modal, kip) ekleri.

Çok farklı olmalarına rağmen, bu fiil çekimlerinin neden Türkçede bir başlık altında ele alındığı tartışmalarına girilmeden, Üsküp Türk ağzındaki zaman ve dilek ekleri alışılagelmiş sıraya göre ele alınacaktır.

Çalışmada fiillerin basit kipli çekimleri ele alınmıştır ve sadece ilginç olan yerlerde birleşik kipli çekimlerden bahsedilmiştir.

\section{Bildirme Kip Ekleri}

Standart Türkçede kullanılan tüm beş bildirme kipi bu ağızda da kullanılmaktadır.

\section{Belirsiz Geçmiş Zaman Kipi}

Németh, Batı Rumeli Türk ağızlarından bahsederken, burada belirsiz geçmiş zaman ekinin her zaman tek varyantlı olduğunu söylemektedir. Bunun nedeni olarak ise, Kowalski'nin sözlerini aktarmaktadır. Kowalski’ye göre, Makedonya Türk ağızlarında kelime sonundaki dar ünlülerden sadece "i” ünlüsü kullanılmaktadır (Kowalski, 1926: 168). Ancak Németh, bunun asıl nedeninin Göktürk yazıtlarına kadar gittiğini iddia eder (Németh, 1983: 134). Aynı çalışmanın sonundaki haritalardan da görüleceği üzere, bu özelliğin tüm Makedonya ağılarında da yaşadığı görülmektedir (Németh, 1983: 164). Makedonya'nın belirli ağızları üzerine yapılan tüm çalışmalardan da bu ekin her zaman tek varyantıyla kullanıldığı görülür. 
Demek ki, Üsküp ağzında da belirsiz geçmiş zaman kipinin eki, kelime sonuda olsun, kelime içinde olsun, her zaman /-miş/ varyantıdır:

\begin{tabular}{|c|c|c|c|c|}
\hline & \multicolumn{2}{|c|}{ OLUMLULUK } & \multicolumn{2}{|c|}{ OLUMSUZLUK } \\
\hline & TEKLIKK & ÇOKLUK & TEKLIK & ÇOKLUK \\
\hline & \multicolumn{4}{|c|}{$a l-$} \\
\hline 1. Ş & al-miş-1m & al-miş-1k & al-ma-miş-1m & al-ma-miş-1k \\
\hline 2. SS & al-miş-ın & al-miş-1nız & al-ma-miş-ın & al-ma-miş-1nız \\
\hline \multirow{2}{*}{ 3. Ş } & al-miş- $\varnothing$ & al-miş-lar & al-ma-miş- $\varnothing$ & al-ma-miş-lar \\
\hline & \multicolumn{4}{|c|}{ başla- } \\
\hline 1. Ş & başla-miş-1m & başla-miş-1k & başla-ma-miş-1m & başla-ma-miş-1k \\
\hline 2. Ş & başla-miş-ın & başla-miş-ınız & başla-ma-miş-ın & $\begin{array}{l}\text { başla-ma-miş- } \\
\text { 1n1z }\end{array}$ \\
\hline \multirow[t]{2}{*}{ 3. SS } & başla-miş- $\varnothing$ & başla-miş-lar & başla-ma-miş- $\varnothing$ & başla-ma-miş-lar \\
\hline & \multicolumn{4}{|c|}{ gür- (<gör-) } \\
\hline 1. Ş & gür-miş-1m & gür-miş-1k & gür-me-miş-1m & gür-me-miş-1k \\
\hline 2. SS & gür-miş-ın & gür-miş-1nız & gür-me-miş-ın & gür-me-miş-1nız \\
\hline \multirow[t]{2}{*}{ 3. SS } & gür-miş- $\varnothing$ & gür-miş-lar & gür-me-miş- $\varnothing$ & gür-me-miş-lar \\
\hline & \multicolumn{4}{|c|}{ oku- } \\
\hline 1. SS & oku-miş-1m & oku-miş-1k & oku-ma-miş-1m & oku-ma-miş-1k \\
\hline 2. SS & oku-miş-1n & oku-miş-1nız & oku-ma-miş-ın & oku-ma-miş-1nız \\
\hline 3. Ş & oku-miş- $\varnothing$ & oku-miş-lar & oku-ma-miş- $\varnothing$ & oku-ma-miş-lar \\
\hline
\end{tabular}




\begin{tabular}{|c|l|l|l|l|}
\hline & \multicolumn{3}{|c|}{ üşü- } \\
\hline $\mathbf{1 .}$ Ş & üşü-miş-1m & üşü-miş-1k & üşü-me-miş-1m & üşü-me-miş-1k \\
\hline $\mathbf{2 .}$ Ş & üşü-miş-1n & üşü-miş-1nız & üşü-me-miş-1n & üşü-me-miş-1nız \\
\hline 3. Ş & üşü-miş-Ø & üşü-miş-lar & üşü-me-miş- $\emptyset$ & üşü-me-miş-lar \\
\hline
\end{tabular}

Görüleceği üzere, bu kip eki kelimenin mutlak sonunda bulunsa da (3. teklik kişide olduğu gibi), bulunmasa da (tüm diğer kişilerde), her zaman tek varyantlıdır.

Belirsiz geçmiş zaman kipinin, tek varyantlı olmasının dışında, Standart Türkçeden hiçbir başka farkı veya farklı kullanımı yoktur.

\section{Belirli Geçmiş Zaman Kipi}

Standart Türkçede sekiz varyantlı olan /-Dİ/ belirli geçmiş zaman kip ekinin Üsküp Türk ağzında da sekiz varyantı vardır, ancak bunlar farklı durumlarda kullanılır.

$\mathrm{Bu}$ kip ekinin, büyük ünlü uyumlarına uymadan kullanıldı̆̆ı göze çarpmaktadır. Aşağıdaki örneklerden şu kuralların hüküm sürdüğünü görmek mümkün:

- Üçüncü kişi teklik ve çoklukta, ekin her zaman “i”li varyantı var. Ekin başındaki ünsüz ise, ünsüz uyumuna göre değişir. Kelimenin mutlak sonunda olsun, ekten sonra kişi eki de gelse, üçüncü kişide teklik ve çoklukta, sadece iki varyantı vardır: /-di/ ve /-ti/.

- Birinci ve ikinci kişi teklik ve çoklukta ise, ekin /-di/ ve /-ti/ varyantları hariç, tüm diğer varyantları kullanılır.

\begin{tabular}{|c|c|c|c|c|}
\hline & \multicolumn{2}{|c|}{ OLUMLULUK } & \multicolumn{2}{|c|}{ OLUMSUZLUK } \\
\hline & TEKLIKK & ÇOKLUK & TEKLIKK & ÇOKLUK \\
\hline & \multicolumn{4}{|c|}{$a l-$} \\
\hline 1. Ş & al-d1-m & al-d1-k & al-ma-d1-m & al-ma-d1-k \\
\hline 2. Ş & al-d1-n & al-d1-n1z & al-ma-d1-n & al-ma-d1-n1z \\
\hline \multirow[t]{2}{*}{ 3. Ş } & al-di- $\varnothing$ & al-di-lar & al-ma-di- $\varnothing$ & al-ma-di-lar \\
\hline & \multicolumn{4}{|c|}{ bak- } \\
\hline
\end{tabular}




\begin{tabular}{|c|c|c|c|c|}
\hline 1. Ş & bak-t1-m & bak-t1-k & bak-ma-d1-m & bak-ma-d1-k \\
\hline 2. Ş & bak-t1-n & bak-t1-n1z & bak-ma-d1-n & bak-ma-d1-n1z \\
\hline 3. Ş & bak-ti- $\varnothing$ & bak-ti-lar & bak-ma-di- $\varnothing$ & bak-ma-di-lar \\
\hline & \multicolumn{4}{|c|}{$c ̧ i k-(<c ̧ ı k-)$} \\
\hline 1. Ş & çik-tı-m & çik-tı-k & çik-ma-d1-m & çik-ma-dı-k \\
\hline 2. Ş & çik-tı-n & çik-tı-nız & çik-ma-d1-n & çik-ma-d1-nız \\
\hline \multirow[t]{2}{*}{ 3. Ş } & çik-ti-Ø & çik-ti-lar & çik-ma-di-Ø & çik-ma-di-lar \\
\hline & \multicolumn{4}{|c|}{ düg- $(<d \ddot{o} v-)$} \\
\hline 1. $S$ S & düg-dü-m & düg-dü-k & düg-me-d1-m & düg-me-d1-k \\
\hline 2. Ş & düg-dü-n & düg-dü-nüz & düg-me-d1-n & düg-me-d1-nız \\
\hline \multirow[t]{2}{*}{ 3. Ş } & düg-di-Ø & düg-di-lar & düg-me-di- $\varnothing$ & düg-me-di-lar \\
\hline & \multicolumn{4}{|c|}{ gel- } \\
\hline 1. Ş & gel-d1-m & gel-d1-k & gel-me-d1-m & gel-me-d1-k \\
\hline 2. Ş & gel-d1-n & gel-d1-n1z & gel-me-d1-n & gel-me-d1-n1z \\
\hline \multirow[t]{2}{*}{ 3. Ş } & gel-di- $\varnothing$ & gel-di-lar & gel-me-di- $\varnothing$ & gel-me-di-lar \\
\hline & \multicolumn{4}{|c|}{$o k u-$} \\
\hline 1. Ş & oku-du-m & oku-du-k & oku-ma-d1-m & oku-ma-d1-k \\
\hline 2. $S$ & oku-du-n & oku-du-nuz & oku-ma-d1-n & oku-ma-d1-n1z \\
\hline \multirow[t]{2}{*}{ 3. Ş } & oku-di- $\varnothing$ & oku-di-lar & oku-ma-di- $\varnothing$ & oku-ma-di-lar \\
\hline & \multicolumn{4}{|c|}{ sük- (<sök-) } \\
\hline
\end{tabular}




\begin{tabular}{|c|c|c|c|c|}
\hline 1. Ş & sük-tü-m & sük-tü-k & sük-me-d1-m & sük-me-d1-k \\
\hline 2. Ş & sük-tü-n & sük-tü-nüz & sük-me-d1-n & sük-me-d1-nız \\
\hline 3. Ş & sük-ti-Ø & sük-ti-lar & sük-me-di- $\emptyset$ & sük-me-di-lar \\
\hline & \multicolumn{4}{|c|}{ tut- } \\
\hline 1. $S$ & tut-tu-m & tut-tu-k & tut-ma-d1-m & tut-ma-d1-k \\
\hline 2. Ş & tut-tu-n & tut-tu-nuz & tut-ma-d1-n & tut-ma-d1-n1z \\
\hline \multirow[t]{2}{*}{ 3. Ş } & tut-ti-Ø & tut-ti-lar & tut-ma-di-Ø & tut-ma-di-lar \\
\hline & \multicolumn{4}{|c|}{ yap- } \\
\hline 1. Ş & yap-t1-m & yap-t1-k & yap-ma-d1-m & yap-ma-d1-k \\
\hline 2. Ş & yap-t1-n & yap-t1-nız & yap-ma-d1-n & yap-ma-d1-n1z \\
\hline 3. Ş & yap-ti- $\varnothing$ & yap-ti-lar & yap-ma-di- $\varnothing$ & yap-ma-di-lar \\
\hline
\end{tabular}

- Bu kip eki, birleşik kipli fiillerde sadece /-di/ ve /-ti/ varyantlarıyla kullanılır.

\begin{tabular}{|c|c|c|c|c|}
\hline & \multicolumn{4}{|c|}{ al- } \\
\hline 1. Ş & al-di-(y)se-m & al-di-(y)se-k & al-ma-di-(y)se-m & al-ma-di-(y)se-k \\
\hline 2. SS & al-di-(y)se-n & al-di-(y)se-n1z & al-ma-di-(y)se-n & al-ma-di-(y)se-nız \\
\hline 3. SS & al-di-(y)se- $\varnothing$ & al-di-(y)se-lar & al-ma-di-(y)se- $\varnothing$ & al-ma-di-(y)se-lar \\
\hline & \multicolumn{4}{|c|}{ yap- } \\
\hline 1. Ş & yap-ti-(y)se-m & yap-ti-(y)se-k & yap-ma-di-(y)se-m & yap-ma-di-(y)se-k \\
\hline 2. SS & yap-ti-(y)se-n & yap-ti-(y)se-nız & yap-ma-di-(y)se-n & $\begin{array}{l}\text { yap-ma-di-(y)se- } \\
\text { n1z }\end{array}$ \\
\hline 3. Ş & yap-ti-(y)se- $\varnothing$ & yap-ti-(y)se-lar & yap-ma-di-(y)se- $\varnothing$ & yap-ma-di-(y)se-lar \\
\hline
\end{tabular}


Kullanımda, sadece ünsüz uyumu vardır.

Belirli geçmiş zaman kipi de, Türkiye Türkçesinden hiçbir başka farkı veya değişik kullanımı yoktur.

\section{Şimdiki Zaman Kipi}

Friedman, Batı Rumeli (o dönemde "Yugoslavya") Türk ağızlarında /-yor/ eki yerine sadece /-y/ şeklinin varlığını ileri sürmüştür (Friedman, 1982: 2). Németh, şimdiki zaman kipinin Üsküp'ün de içinde bulunduğu Batı Rumeli ağzının en belirgin özelliklerinden biri olduğunu iddia eder ve temel olan /-y/ biçiminin yanısıra, /-i/ biçimin de varlığından haberdar eder, ancak ne zaman /-y/ ne zaman da /-i// varyantının kullanıldığına dair kuralları ortaya koymamıştır (Németh, 1983: 127-128, 167).

XIX. yüzyıl Türk ağızlarında kısmen kullanıldığını Pulevski’nin sözlüklerinden görülebilir (Ahmed, 2012b), ancak bu kullanımların daha çok eğitim görmüş kişilerde rastlandığ1 iddia edilebilir. Üsküp Türk ağzında Standart Türkçedeki /-yor/ biçimi bugün kesinlikle kullanılmaz. Bu şekil, bugün bütün yaşayan Batı Rumeli Türk ağızlarında da kesinlikle kullanılmamaktadır. (Ahmed, 2014: 4-6).

Üsküp ağzında morfolojik şimdiki zaman, semantik geniş zaman için de kullanılmaktadır. Diğer sözlerle, Makedonya'nın güney ağızlarında morfolojik geniş zamanla semantik şimdiki zaman kapsandığ 1 gibi, Üsküp ağzında da şimdiki zaman biçimleriyle anlamca geniş zaman ifade edilmektedir (Ahmed, 2014: 4).

Ünlüyle biten tüm fiil kök veya gövdelerine doğrudan doğruya sadece /-y/ varyantı eklenir:

\begin{tabular}{|c|c|c|c|c|}
\hline & \multicolumn{2}{|c|}{ OLUMLULUK } & \multicolumn{2}{|c|}{ OLUMSUZLUK } \\
\hline & TEKLIK & ÇOKLUK & TEKLIK & ÇOKLUK \\
\hline & \multicolumn{4}{|c|}{$a c l-$} \\
\hline 1. Ş & ac1-y-m & ac1-y-s & ac1-ma-y-m & ac1-ma-y-s \\
\hline 2. SS & ac1-y-sin & ac1-y-sin1z & ac1-ma-y-sin & ac1-ma-y-sin1z \\
\hline \multirow[t]{2}{*}{ 3. SS } & ac1-y-Ø & ac1-y-lar & ac1-ma-y- & ac1-ma-y-lar \\
\hline & \multicolumn{4}{|c|}{ agla $-(<$ ağla -$)$} \\
\hline 1. SS & agla-y-m & agla-y-s & agla-ma-y-m & agla-ma-y-s \\
\hline
\end{tabular}




\begin{tabular}{|c|c|c|c|c|}
\hline 2. Ş & agla-y-sin & agla-y-siniz & agla-ma-y-sin & agla-ma-y-sinız \\
\hline 3. Ş & agla-y-Ø & agla-y-lar & agla-ma-y-Ø & agla-ma-y-lar \\
\hline & \multicolumn{4}{|c|}{ ara- } \\
\hline 1. Ş & ara-y-m & ara-y-s & ara-ma-y-m & ara-ma-y-s \\
\hline 2. Ş & ara-y-sin & ara-y-sinız & ara-ma-y-sin & ara-ma-y-sinız \\
\hline \multirow[t]{2}{*}{ 3. Ş } & ara-y- $\varnothing$ & ara-y-lar & ara-ma-y- $\varnothing$ & ara-ma-y-lar \\
\hline & \multicolumn{4}{|c|}{ buna- } \\
\hline 1. SS & buna-y-m & buna-y-s & buna-ma-y-m & buna-ma-y-s \\
\hline 2. SS & buna-y-sin & buna-y-sin1z & buna-ma-y-sın & buna-ma-y-siniz \\
\hline \multirow[t]{2}{*}{ 3. SS } & buna-y-Ø & buna-y-lar & buna-ma-y-Ø & buna-ma-y-lar \\
\hline & \multicolumn{4}{|c|}{$i k a-(<y l k a-)$} \\
\hline 1. Ş & ika-y-m & ika-y-s & ika-ma-y-m & ika-ma-y-s \\
\hline 2. Ş & ika-y-sin & ika-y-sinız & ika-ma-y-sin & ika-ma-y-sınız \\
\hline \multirow[t]{2}{*}{ 3. Ş } & ika-y-Ø & ika-y-lar & ika-ma-y- $\varnothing$ & ika-ma-y-lar \\
\hline & \multicolumn{4}{|c|}{ kapsa- } \\
\hline 1. Ş & kapsa-y-m & kapsa-y-s & kapsa-ma-y-m & kapsa-ma-y-s \\
\hline 2. SS & kapsa-y-sin & kapsa-y-sınız & kapsa-ma-y-sin & $\begin{array}{l}\text { kapsa-ma-y- } \\
\text { sinız }\end{array}$ \\
\hline \multirow[t]{2}{*}{ 3. SS } & kapsa-y-Ø & kapsa-y-lar & kapsa-ma-y-Ø & kapsa-ma-y-lar \\
\hline & \multicolumn{4}{|c|}{ kaşı- } \\
\hline 1. Ş & kaşı-y-m & kaşı-y-s & kaş1-ma-y-m & kaş1-ma-y-s \\
\hline
\end{tabular}




\begin{tabular}{|c|c|c|c|c|}
\hline 2. Ş & kaşı-y-sın & kaşı-y-sınız & kaşı-ma-y-sın & kaşı-ma-y-sınız \\
\hline 3. Ş & kaşı-y-Ø & kaş1-y-lar & kaşı-ma-y-Ø & kaş1-ma-y-lar \\
\hline & \multicolumn{4}{|c|}{ oku- } \\
\hline 1. Ş & oku-y-m & oku-y-s & oku-ma-y-m & oku-ma-y-s \\
\hline 2. Ş & oku-y-sin & oku-y-sinız & oku-ma-y-sin & oku-ma-y-sinız \\
\hline \multirow[t]{2}{*}{ 3. SS } & oku-y- $\varnothing$ & oku-y-lar & oku-ma-y-Ø & oku-ma-y-lar \\
\hline & \multicolumn{4}{|c|}{ otala- (zehirle-) } \\
\hline 1. Ş & otala-y-m & otala-y-s & otala-ma-y-m & otala-ma-y-s \\
\hline 2. SS & otala-y-sin & otala-y-sin1z & otala-ma-y-sin & otala-ma-y-siniz \\
\hline \multirow[t]{2}{*}{ 3. SS } & otala-y-Ø & otala-y-lar & otala-ma-y- & otala-ma-y-lar \\
\hline & \multicolumn{4}{|c|}{ süle- $(<$ söyle-) } \\
\hline 1. Ş & süle-y-m & süle-y-s & süle-me-y-m & süle-me-y-s \\
\hline 2. Ş & süle-y-sin & süle-y-sin1z & süle-me-y-sın & süle-me-y-sınız \\
\hline \multirow[t]{2}{*}{ 3. Ş } & süle-y-Ø & süle-y-lar & süle-me-y-Ø & süle-me-y-lar \\
\hline & \multicolumn{4}{|c|}{ tara- } \\
\hline 1. SS & tara-y-m & tara-y-s & tara-ma-y-m & tara-ma-y-s \\
\hline 2. SS & tara-y-sin & tara-y-sin1z & tara-ma-y-sin & tara-ma-y-sinız \\
\hline \multirow[t]{2}{*}{ 3. SS } & tara-y- $\varnothing$ & tara-y-lar & tara-ma-y-Ø & tara-ma-y-lar \\
\hline & \multicolumn{4}{|c|}{ üde- $(<\ddot{o d e}-)$} \\
\hline 1. Ş & üde-y-m & üde-y-s & üde-me-y-m & üde-me-y-s \\
\hline
\end{tabular}




\begin{tabular}{|c|c|c|c|c|}
\hline 2. Ş & üde-y-sın & üde-y-sin1z & üde-me-y-sin & üde-me-y-sinız \\
\hline 3. Ş & üde-y-Ø & üde-y-lar & üde-me-y-Ø & üde-me-y-lar \\
\hline & \multicolumn{4}{|c|}{ иуи- } \\
\hline 1. Ş & uyu-y-m & uyu-y-s & uyu-ma-y-m & uyu-ma-y-s \\
\hline 2. Ş & uyu-y-sin & uyu-y-sinız & uyu-ma-y-sin & uyu-ma-y-sinız \\
\hline \multirow[t]{2}{*}{ 3. SS } & uyu-y-Ø & uyu-y-lar & uyu-ma-y-Ø & uyu-ma-y-lar \\
\hline & \multicolumn{4}{|c|}{ yaşa- } \\
\hline 1. Ş & yaşa-y-m & yaşa-y-s & yaşa-ma-y-m & yaşa-ma-y-s \\
\hline 2. SS & yaşa-y-sın & yaşa-y-sınız & yaşa-ma-y-sın & yaşa-ma-y-sinız \\
\hline \multirow[t]{2}{*}{ 3. SS } & yaşa-y-Ø & yaşa-y-lar & yaşa-ma-y- $\varnothing$ & yaşa-ma-y-lar \\
\hline & \multicolumn{4}{|c|}{$y e-$} \\
\hline 1. SS & ye-y-m & ye-y-s & ye-me-y-m & ye-me-y-s \\
\hline 2. SS & ye-y-sin & ye-y-sin1z & ye-me-y-sin & ye-me-y-sin1z \\
\hline 3. Ş & ye-y-Ø & ye-y-lar & ye-me-y-Ø & ye-me-y-lar \\
\hline
\end{tabular}

Ünsüzle biten fiil köklerine ise /-Ay/ varyantı eklenir:

\begin{tabular}{|c|c|c|c|c|}
\hline & \multicolumn{2}{|c|}{ OLUMLULUK } & \multicolumn{2}{|c|}{ OLUMSUZLUK } \\
\hline & TEKLIK & ÇOKLUK & TEKLIK & ÇOKLUK \\
\hline & \multicolumn{4}{|c|}{$a k-$} \\
\hline 1. Ş & ak-ay-m & ak-ay-s & ak-ma-y-m & ak-ma-y-s \\
\hline 2. Ş & ak-ay-sin & ak-ay-sinız & ak-ma-y-sin & ak-ma-y-siniz \\
\hline
\end{tabular}




\begin{tabular}{|c|c|c|c|c|}
\hline 3. Ş & ak-ay- $\varnothing$ & ak-ay-lar & ak-ma-y-Ø & ak-ma-y-lar \\
\hline & \multicolumn{4}{|c|}{$a s-$} \\
\hline 1. SS & as-ay-m & as-ay-s & as-ma-y-m & as-ma-y-s \\
\hline 2. SS & as-ay-sin & as-ay-sinız & as-ma-y-sin & as-ma-y-sinız \\
\hline \multirow[t]{2}{*}{ 3. Ş } & as-ay- $\varnothing$ & as-ay-lar & as-ma-y-Ø & as-ma-y-lar \\
\hline & \multicolumn{4}{|c|}{ bak- } \\
\hline 1. Ş & bak-ay-m & bak-ay-s & bak-ma-y-m & bak-ma-y-s \\
\hline 2. SS & bak-ay-sın & bak-ay-sınız & bak-ma-y-sin & bak-ma-y-sinız \\
\hline \multirow[t]{2}{*}{ 3. SS } & bak-ay- $\varnothing$ & bak-ay-lar & bak-ma-y-Ø & bak-ma-y-lar \\
\hline & \multicolumn{4}{|c|}{ biç- } \\
\hline 1. Ş & biç-ey-m & biç-ey-s & biç-me-y-m & biç-me-y-s \\
\hline 2. Ş & biç-ey-sin & biç-ey-sınız & biç-me-y-sın & biç-me-y-sınız \\
\hline \multirow[t]{2}{*}{ 3. Ş } & biç-ey-Ø & biç-ey-lar & biç-me-y- $\varnothing$ & biç-me-y-lar \\
\hline & \multicolumn{4}{|c|}{ dal- } \\
\hline 1. SS & dal-ay-m & dal-ay-s & dal-ma-y-m & dal-ma-y-s \\
\hline 2. Ş & dal-ay-sin & dal-ay-sinız & dal-ma-y-sin & dal-ma-y-sinız \\
\hline \multirow[t]{2}{*}{ 3. Ş } & dal-ay- $\varnothing$ & dal-ay-lar & dal-ma-y-Ø & dal-ma-y-lar \\
\hline & \multicolumn{4}{|c|}{ don- } \\
\hline 1. Ş & don-ay-m & don-ay-s & don-ma-y-m & don-ma-y-s \\
\hline 2. Ş & don-ay-sin & don-ay-sin1z & don-ma-y-sin & don-ma-y-siniz \\
\hline
\end{tabular}




\begin{tabular}{|c|c|c|c|c|}
\hline 3. Ş & don-ay- $\varnothing$ & don-ay-lar & don-ma-y-Ø & don-ma-y-lar \\
\hline & \multicolumn{4}{|c|}{ dün- (<dön-) } \\
\hline 1. SS & dün-ey-m & dün-ey-s & dün-me-y-m & dün-me-y-s \\
\hline 2. Ş & dün-ey-sin & dün-ey-sin1z & dün-me-y-sin & dün-me-y-sinız \\
\hline \multirow[t]{2}{*}{ 3. Ş } & dün-ey-Ø & dün-ey-lar & dün-me-y-Ø & dün-me-y-lar \\
\hline & \multicolumn{4}{|c|}{$e n-(<i n-)$} \\
\hline 1. SS & en-ey-m & en-ey-s & en-me-y-m & en-me-y-s \\
\hline 2. SS & en-ey-sin & en-ey-siniz & en-me-y-sin & en-me-y-sin1z \\
\hline \multirow[t]{2}{*}{ 3. SS } & en-ey-Ø & en-ey-lar & en-me-y- $\varnothing$ & en-me-y-lar \\
\hline & \multicolumn{4}{|c|}{$i c ̧-$} \\
\hline 1. Ş & iç-ey-m & iç-ey-s & iç-me-y-m & iç-me-y-s \\
\hline 2. Ş & iç-ey-sın & iç-ey-sınız & iç-me-y-sin & iç-me-y-sınız \\
\hline \multirow[t]{2}{*}{ 3. SS } & iç-ey-Ø & iç-ey-lar & iç-me-y-Ø & iç-me-y-lar \\
\hline & \multicolumn{4}{|c|}{ san- } \\
\hline 1. SS & san-ay-m & san-ay-s & san-ma-y-m & san-ma-y-s \\
\hline 2. SS & san-ay-sin & san-ay-sinız & san-ma-y-sin & san-ma-y-sin1z \\
\hline \multirow[t]{2}{*}{ 3. Ş } & san-ay- $\varnothing$ & san-ay-lar & san-ma-y-Ø & san-ma-y-lar \\
\hline & \multicolumn{4}{|c|}{ sar- } \\
\hline 1. Ş & sar-ay-m & sar-ay-s & sar-ma-y-m & sar-ma-y-s \\
\hline 2. SS & sar-ay-sin & sar-ay-sin1z & sar-ma-y-sin & sar-ma-y-sinız \\
\hline
\end{tabular}




\begin{tabular}{|c|c|c|c|c|}
\hline 3. Ş & sar-ay-Ø & sar-ay-lar & sar-ma-y-Ø & sar-ma-y-lar \\
\hline & \multicolumn{4}{|c|}{ sev- } \\
\hline 1. Ş & sev-ey-m & sev-ey-s & sev-me-y-m & sev-me-y-s \\
\hline 2. Ş & sev-ey-sin & sev-ey-sinız & sev-me-y-sin & sev-me-y-siniz \\
\hline \multirow[t]{2}{*}{ 3. Ş } & sev-ey-Ø & sev-ey-lar & sev-me-y-Ø & sev-me-y-lar \\
\hline & \multicolumn{4}{|c|}{$u c ̧-$} \\
\hline 1. Ş & uç-ay-m & uç-ay-s & uç-ma-y-m & uç-ma-y-s \\
\hline 2. Ş & uç-ay-sın & uç-ay-sınız & uç-ma-y-sın & uç-ma-y-sınız \\
\hline \multirow[t]{2}{*}{ 3. Ş } & uç-ay-Ø & uç-ay-lar & uç-ma-y-Ø & uç-ma-y-lar \\
\hline & \multicolumn{4}{|c|}{ yag- $\left(<y a \breve{g}_{-}\right)$} \\
\hline 1. Ş & yag-ay-m & yag-ay-s & yag-ma-y-m & yag-ma-y-s \\
\hline 2. Ş & yag-ay-sin & yag-ay-sınız & yag-ma-y-sın & yag-ma-y-sinız \\
\hline 3. Ş & yag-ay- $\varnothing$ & yag-ay-lar & yag-ma-y-Ø & yag-ma-y-lar \\
\hline
\end{tabular}

Bunlardan, "l” ve "r" ünsüzleriyle biten fiillere /-i/ varyantı eklenmektedir:

\begin{tabular}{|c|c|c|c|c|}
\hline & \multicolumn{2}{|c|}{ OLUMLULUK } & \multicolumn{2}{|c|}{ OLUMSUZLUK } \\
\hline & TEKLIK & ÇOKLUK & TEKLIK & ÇOKLUK \\
\hline & \multicolumn{4}{|c|}{$a l-$} \\
\hline 1. SS & al-i-m & al-i-s & al-ma-y-m & al-ma-y-s \\
\hline 2. Ş & al-i-sin & al-i-sin1z & al-ma-y-sin & al-ma-y-sin1z \\
\hline
\end{tabular}




\begin{tabular}{|c|c|c|c|c|}
\hline 3. SS & al-i- $\varnothing$ & al-i-lar & al-ma-y-Ø & al-ma-y-lar \\
\hline & \multicolumn{4}{|c|}{ aylr- } \\
\hline 1. SS & ayır-i-m & ayır-i-s & ayır-ma-y-m & ayır-ma-y-s \\
\hline 2. Ş & ayır-i-sin & ayır-i-sinız & ayır-ma-y-sin & ayır-ma-y-sinız \\
\hline \multirow[t]{2}{*}{ 3. Ş } & ayır-i-Ø & ayır-i-lar & ayır-ma-y-Ø & ayır-ma-y-lar \\
\hline & \multicolumn{4}{|c|}{ bul- } \\
\hline 1. Ş & bul-i-m & bul-i-s & bul-ma-y-m & bul-ma-y-s \\
\hline 2. SS & bul-i-sin & bul-i-sinız & bul-ma-y-sin & bul-ma-y-sinız \\
\hline \multirow[t]{2}{*}{ 3. SS } & bul-i-Ø & bul-i-lar & bul-ma-y-Ø & bul-ma-y-lar \\
\hline & \multicolumn{4}{|c|}{ gel- } \\
\hline 1. Ş & gel-i-m & gel-i-s & gel-me-y-m & gel-me-y-s \\
\hline 2. SS & gel-i-sin & gel-i-sinız & gel-me-y-sin & gel-me-y-sinız \\
\hline \multirow[t]{2}{*}{ 3. SS } & gel-i-Ø & gel-i-lar & gel-me-y-Ø & gel-me-y-lar \\
\hline & \multicolumn{4}{|c|}{ kabar- } \\
\hline 1. SS & kabar-i-m & kabar-i-s & kabar-ma-y-m & kabar-ma-y-s \\
\hline 2. SS & kabar-i-sin & kabar-i-sinız & kabar-ma-y-sın & $\begin{array}{l}\text { kabar-ma-y- } \\
\text { sinız }\end{array}$ \\
\hline \multirow[t]{2}{*}{ 3. Ş } & kabar-i-Ø & kabar-i-lar & kabar-ma-y-Ø & kabar-ma-y-lar \\
\hline & \multicolumn{4}{|c|}{ ol- } \\
\hline 1. SS & ol-i-m & ol-i-s & ol-ma-y-m & ol-ma-y-s \\
\hline 2. SS & ol-i-sin & ol-i-sin1z & ol-ma-y-sin & ol-ma-y-sin1z \\
\hline
\end{tabular}




\begin{tabular}{|c|c|c|c|c|}
\hline 3. Ş & ol-i-Ø & ol-i-lar & ol-ma-y-Ø & ol-ma-y-lar \\
\hline & \multicolumn{4}{|c|}{$\ddot{u} l-(<\ddot{o l} l-)$} \\
\hline 1. Ş & ül-i-m & ül-i-s & ül-me-y-m & ül-me-y-s \\
\hline 2. Ş & ül-i-sin & ül-i-sinız & ül-me-y-sin & ül-me-y-sın1z \\
\hline \multirow[t]{2}{*}{ 3. Ş } & ül-i- $\varnothing$ & ül-i-lar & ül-me-y-Ø & ül-me-y-lar \\
\hline & \multicolumn{4}{|c|}{ ver- } \\
\hline 1. Ş & ver-i-m & ver-i-s & ver-me-y-m & ver-me-y-s \\
\hline 2. Ş & ver-i-sin & ver-i-sinız & ver-me-y-sin & ver-me-y-sinız \\
\hline 3. Ş & ver-i- $\varnothing$ & ver-i-lar & ver-me-y-Ø & ver-me-y-lar \\
\hline
\end{tabular}

Fiilden fiil yapma ekleri, daha doğrusu çatı eklerinden sonra da şimdiki zamanın /-i/ varyantı kullanılır. Bu varyant, çatı eklerinin üst üste gelme durumunda da kullanılmaktadır:

\begin{tabular}{|c|c|c|c|c|}
\hline & \multicolumn{2}{|c|}{ OLUMLULUK } & \multicolumn{2}{|c|}{ OLUMSUZLUK } \\
\hline & TEKLIKK & ÇOKLUK & TEKLİK & ÇOKLUK \\
\hline & \multicolumn{4}{|c|}{ abartır- $(<a b a r t-)$} \\
\hline 1. Ş & abartır-i-m & abartır-i-s & abartır-ma-y-m & abartır-ma-y-s \\
\hline 2. Ş & abartır-i-sin & abartır-i-siniz & abartır-ma-y-sin & abartır-ma-y-sinız \\
\hline \multirow[t]{2}{*}{ 3. Ş } & abartır-i- $\varnothing$ & abartır-i-lar & abartır-ma-y- & abartır-ma-y-lar \\
\hline & \multicolumn{4}{|c|}{ açıl- } \\
\hline 1. Ş & açıl-i-m & aç1l-i-s & aç1l-ma-y-m & aç1l-ma-y-s \\
\hline
\end{tabular}




\begin{tabular}{|c|c|c|c|c|}
\hline 2. Ş & açı1-i-sın & açı1-i-sın1z & aç1l-ma-y-sın & açı1-ma-y-sınız \\
\hline 3. Ş & aç1l-i-Ø & açı1-i-lar & aç11-ma-y-Ø & aç1l-ma-y-lar \\
\hline & \multicolumn{4}{|c|}{ acin- } \\
\hline 1. Ş & acın-i-m & acin-i-s & acin-ma-y-m & acin-ma-y-s \\
\hline 2. Ş & acin-i-sin & acin-i-sinız & acin-ma-y-sin & acin-ma-y-sinız \\
\hline \multirow[t]{2}{*}{ 3. SS } & acin-i- $\varnothing$ & acin-i-lar & acin-ma-y- $\varnothing$ & acın-ma-y-lar \\
\hline & \multicolumn{4}{|c|}{ agartır- (<ăgart-) } \\
\hline 1. Ş & agartır-i-m & agartır-i-s & agartır-ma-y-m & agartır-ma-y-s \\
\hline 2. Ş & agartır-i-sin & agartır-i-sinız & agartır-ma-y-sin & agartır-ma-y-sinız \\
\hline \multirow[t]{2}{*}{ 3. Ş } & agartır-i- $\varnothing$ & agartır-i-lar & agartır-ma-y-Ø & agartır-ma-y-lar \\
\hline & \multicolumn{4}{|c|}{ aglaş- $(<$ şikayet et- $)$} \\
\hline 1. Ş & aglaş-i-m & aglaş-i-s & aglaş-ma-y-m & aglaş-ma-y-s \\
\hline 2. Ş & aglaş-i-sın & aglaş-i-sınız & aglaş-ma-y-sın & aglaş-ma-y-sınız \\
\hline \multirow[t]{2}{*}{ 3. Ş } & aglaş-i- $\varnothing$ & aglaş-i-lar & aglaş-ma-y-Ø & aglaş-ma-y-lar \\
\hline & \multicolumn{4}{|c|}{ aklt- } \\
\hline 1. Ş & akıt-i-m & akit-i-s & akit-ma-y-m & akit-ma-y-s \\
\hline 2. SS & akit-i-sin & akıt-i-sinız & akit-ma-y-sin & akıt-ma-y-sinız \\
\hline \multirow[t]{2}{*}{ 3. SS } & akıt-i- $\varnothing$ & akit-i-lar & akıt-ma-y-Ø & akıt-ma-y-lar \\
\hline & \multicolumn{4}{|c|}{ aktar- } \\
\hline 1. Ş & aktar-i-m & aktar-i-s & aktar-ma-y-m & aktar-ma-y-s \\
\hline
\end{tabular}




\begin{tabular}{|c|c|c|c|c|}
\hline 2. Ş & aktar-i-sin & aktar-i-sınız & aktar-ma-y-sin & aktar-ma-y-sinız \\
\hline 3. Ş & aktar-i- $\varnothing$ & aktar-i-lar & aktar-ma-y- & aktar-ma-y-lar \\
\hline & \multicolumn{4}{|c|}{ aldatır- (<aldat- $)$} \\
\hline 1. Ş & aldatır-i-m & aldatır-i-s & aldatır-ma-y-m & aldatır-ma-y-s \\
\hline 2. Ş & aldatır-i-sin & aldatır-i-sinız & aldatır-ma-y-sin & aldatır-ma-y-siniz \\
\hline \multirow[t]{2}{*}{ 3. SS } & aldatır-i- $\varnothing$ & aldatır-i-lar & aldatır-ma-y-Ø & aldatır-ma-y-lar \\
\hline & \multicolumn{4}{|c|}{ aldır- } \\
\hline 1. Ş & aldir-i-m & aldır-i-s & aldır-ma-y-m & aldir-ma-y-s \\
\hline 2. Ş & aldir-i-sin & aldır-i-sinız & aldir-ma-y-sin & aldir-ma-y-sınız \\
\hline \multirow[t]{2}{*}{ 3. SS } & aldir-i- $\varnothing$ & aldir-i-lar & aldır-ma-y- $\varnothing$ & aldır-ma-y-lar \\
\hline & \multicolumn{4}{|c|}{ alın- } \\
\hline 1. Ş & alın-i-m & alın-i-s & alın-ma-y-m & alın-ma-y-s \\
\hline 2. SS & alın-i-sin & alın-i-sinız & alın-ma-y-sın & alın-ma-y-sinız \\
\hline \multirow[t]{2}{*}{ 3. Ş } & alın-i-Ø & alın-i-lar & alın-ma-y-Ø & alın-ma-y-lar \\
\hline & \multicolumn{4}{|c|}{ anlaş- } \\
\hline 1. SS & anlaş-i-m & anlaş-i-s & anlaş-ma-y-m & anlaş-ma-y-s \\
\hline 2. SS & anlaş-i-sın & anlaş-i-sınız & anlaş-ma-y-sın & anlaş-ma-y-sınız \\
\hline \multirow[t]{2}{*}{ 3. SS } & anlaş-i- $\varnothing$ & anlaş-i-lar & anlaş-ma-y-Ø & anlaş-ma-y-lar \\
\hline & \multicolumn{4}{|c|}{ anlat- } \\
\hline 1. Ş & anlat-i-m & anlat-i-s & anlat-ma-y-m & anlat-ma-y-s \\
\hline
\end{tabular}




\begin{tabular}{|c|c|c|c|c|}
\hline 2. Ş & anlat-i-sin & anlat-i-sin1z & anlat-ma-y-sin & anlat-ma-y-sinız \\
\hline 3. Ş & anlat-i- $\varnothing$ & anlat-i-lar & anlat-ma-y- $\varnothing$ & anlat-ma-y-lar \\
\hline & \multicolumn{4}{|c|}{ apşır - (<hapşırmak, aksırmak) } \\
\hline 1. Ş & apşır-i-m & apşır-i-s & apşır-ma-y-m & apşır-ma-y-s \\
\hline 2. Ş & apşır-i-sın & apşır-i-sın1z & apşır-ma-y-sın & apşır-ma-y-sınız \\
\hline \multirow[t]{2}{*}{ 3. SS } & apşır-i-Ø & apşır-i-lar & apşır-ma-y-Ø & apşır-ma-y-lar \\
\hline & \multicolumn{4}{|c|}{ aran- } \\
\hline 1. Ş & $\operatorname{aran}-\mathrm{i}-\mathrm{m}$ & aran-i-s & aran-ma-y-m & aran-ma-y-s \\
\hline 2. SS & aran-i-sin & $\operatorname{aran}-\mathrm{i}-\sin 1 z$ & aran-ma-y-sin & aran-ma-y-sinız \\
\hline \multirow[t]{2}{*}{ 3. Ş } & $\operatorname{aran}-\mathrm{i}-\varnothing$ & aran-i-lar & aran-ma-y- & aran-ma-y-lar \\
\hline & \multicolumn{4}{|c|}{ arantl- } \\
\hline 1. SS & aran1l-i-m & aran1l-i-s & aran11-ma-y-m & aran1l-ma-y-s \\
\hline 2. Ş & aranıl-i-sin & aranıl-i-sinız & aranil-ma-y-sin & aran1l-ma-y-siniz \\
\hline \multirow[t]{2}{*}{ 3. Ş } & aran1l-i-Ø & aranıl-i-lar & aranıl-ma-y-Ø & aran1l-ma-y-lar \\
\hline & \multicolumn{4}{|c|}{ artır- } \\
\hline 1. Ş & artır-i-m & artır-i-s & artır-ma-y-m & artır-ma-y-s \\
\hline 2. SS & artır-i-sin & $\operatorname{artır}-\mathrm{i}-\sin 1 \mathrm{z}$ & artır-ma-y-sin & artır-ma-y-sinız \\
\hline \multirow[t]{2}{*}{ 3. Ş } & artır-i- $\varnothing$ & artır-i-lar & artır-ma-y-Ø & artır-ma-y-lar \\
\hline & \multicolumn{4}{|c|}{ astor- } \\
\hline 1. Ş & astır-i-m & astır-i-s & astır-ma-y-m & astır-ma-y-s \\
\hline
\end{tabular}




\begin{tabular}{|c|c|c|c|c|}
\hline 2. Ş & astır-i-sin & astır-i-sinız & astır-ma-y-sin & astır-ma-y-sınız \\
\hline 3. Ş & astır-i- $\varnothing$ & astır-i-lar & astır-ma-y- $\varnothing$ & astır-ma-y-lar \\
\hline & \multicolumn{4}{|c|}{ attur- } \\
\hline 1. Ş & attır-i-m & attır-i-s & attır-ma-y-m & attır-ma-y-s \\
\hline 2. Ş & attır-i-sin & attır-i-sinız & attır-ma-y-sin & attır-ma-y-sinız \\
\hline \multirow[t]{2}{*}{ 3. SS } & attır-i- $\varnothing$ & attır-i-lar & attır-ma-y- $\varnothing$ & attır-ma-y-lar \\
\hline & \multicolumn{4}{|c|}{ ayırt- } \\
\hline 1. Ş & ayırt-i-m & ayırt-i-s & ayırt-ma-y-m & ayırt-ma-y-s \\
\hline 2. SS & ayırt-i-sin & ayırt-i-sin1z & ayırt-ma-y-sin & ayırt-ma-y-sinız \\
\hline \multirow[t]{2}{*}{ 3. Ş } & ayırt-i- $\varnothing$ & ayırt-i-lar & ayırt-ma-y- $\varnothing$ & ayırt-ma-y-lar \\
\hline & \multicolumn{4}{|c|}{ bakın- } \\
\hline 1. Ş & bakın-i-m & bakın-i-s & bakın-ma-y-m & bakın-ma-y-s \\
\hline 2. Ş & bakın-i-sın & bakın-i-sin1z & bakın-ma-y-sın & bakın-ma-y-sinız \\
\hline \multirow[t]{2}{*}{ 3. Ş } & bakın-i-Ø & bakın-i-lar & bakın-ma-y-Ø & bakın-ma-y-lar \\
\hline & \multicolumn{4}{|c|}{ basil- } \\
\hline 1. Ş & bas1l-i-m & bas1l-i-s & basıl-ma-y-m & basıl-ma-y-s \\
\hline 2. SS & basil-i-sin & basıl-i-sin1z & basıl-ma-y-sın & bas1l-ma-y-sinız \\
\hline \multirow[t]{2}{*}{ 3. SS } & bas1l-i- $\varnothing$ & basıl-i-lar & basıl-ma-y- & bas1l-ma-y-lar \\
\hline & \multicolumn{4}{|c|}{ başlan- } \\
\hline 1. Ş & başlan-i-m & başlan-i-s & başlan-ma-y-m & başlan-ma-y-s \\
\hline
\end{tabular}




\begin{tabular}{|c|c|c|c|c|}
\hline 2. Ş & başlan-i-sin & başlan-i-sınız & başlan-ma-y-sin & başlan-ma-y-sınız \\
\hline 3. Ş & başlan-i-Ø & başlan-i-lar & başlan-ma-y-Ø & başlan-ma-y-lar \\
\hline & \multicolumn{4}{|c|}{ biçtır- } \\
\hline 1. Ş & biçtır-i-m & biçtır-i-s & biçtır-me-y-m & biçtır-me-y-s \\
\hline 2. Ş & biçtır-i-sın & biçtır-i-sınız & biçtır-me-y-sın & biçtır-me-y-sınız \\
\hline \multirow[t]{2}{*}{ 3. SS } & biçtır-i- $\varnothing$ & biçtır-i-lar & biçtır-me-y- $\varnothing$ & biçtır-me-y-lar \\
\hline & \multicolumn{4}{|c|}{ bozdur- } \\
\hline 1. Ş & bozdur-i-m & bozdur-i-s & bozdur-ma-y-m & bozdur-ma-y-s \\
\hline 2. SS & bozdur-i-sin & bozdur-i-sin1z & bozdur-ma-y-sin & bozdur-ma-y-sinız \\
\hline \multirow[t]{2}{*}{ 3. SS } & bozdur-i- $\varnothing$ & bozdur-i-lar & bozdur-ma-y- $\varnothing$ & bozdur-ma-y-lar \\
\hline & \multicolumn{4}{|c|}{ bozdurt- } \\
\hline 1. Ş & bozdurt-i-m & bozdurt-i-s & bozdurt-ma-y-m & bozdurt-ma-y-s \\
\hline 2. Ş & bozdurt-i-sin & bozdurt-i-siniz & bozdurt-ma-y-sin & bozdurt-ma-y-siniz \\
\hline \multirow[t]{2}{*}{ 3. Ş } & bozdurt-i- $\varnothing$ & bozdurt-i-lar & bozdurt-ma-y-Ø & bozdurt-ma-y-lar \\
\hline & \multicolumn{4}{|c|}{ bulaş- } \\
\hline 1. SS & bulaş-i-m & bulaş-i-s & bulaş-ma-y-m & bulaş-ma-y-s \\
\hline 2. SS & bulaş-i-sın & bulaş-i-sınız & bulaş-ma-y-sın & bulaş-ma-y-sınız \\
\hline \multirow[t]{2}{*}{ 3. SS } & bulaş-i- $\varnothing$ & bulaş-i-lar & bulaş-ma-y- $\varnothing$ & bulaş-ma-y-lar \\
\hline & \multicolumn{4}{|c|}{ bunal- } \\
\hline 1. Ş & bunal-i-m & bunal-i-s & bunal-ma-y-m & bunal-ma-y-s \\
\hline
\end{tabular}




\begin{tabular}{|c|c|c|c|c|}
\hline 2. SS & bunal-i-sın & bunal-i-sin1z & bunal-ma-y-sin & bunal-ma-y-sinız \\
\hline 3. Ş & bunal-i- $\varnothing$ & bunal-i-lar & bunal-ma-y-Ø & bunal-ma-y-lar \\
\hline & \multicolumn{4}{|c|}{ bunalt- } \\
\hline 1. Ş & bunalt-i-m & bunalt-i-s & bunalt-ma-y-m & bunalt-ma-y-s \\
\hline 2. Ş & bunalt-i-sin & bunalt-i-sin1z & bunalt-ma-y-sin & bunalt-ma-y-sin1z \\
\hline \multirow[t]{2}{*}{ 3. SS } & bunalt-i- $\varnothing$ & bunalt-i-lar & bunalt-ma-y- $\varnothing$ & bunalt-ma-y-lar \\
\hline & \multicolumn{4}{|c|}{ çatlat- } \\
\hline 1. Ş & çatlat-i-m & çatlat-i-s & çatlat-ma-y-m & çatlat-ma-y-s \\
\hline 2. Ş & çatlat-i-sin & çatlat-i-sınız & çatlat-ma-y-sın & çatlat-ma-y-sinız \\
\hline \multirow[t]{2}{*}{ 3. Ş } & çatlat-i- $\varnothing$ & çatlat-i-lar & çatlat-ma-y-Ø & çatlat-ma-y-lar \\
\hline & \multicolumn{4}{|c|}{ damlatır- (<damlat-) } \\
\hline 1. Ş & damlatır-i-m & damlatır-i-s & damlatır-ma-y-m & damlatır-ma-y-s \\
\hline 2. Ş & damlatır-i-sin & damlatır-i-sinız & damlatır-ma-y-sin & damlatır-ma-y-sinız \\
\hline \multirow[t]{2}{*}{ 3. SS } & damlatır-i- $\varnothing$ & damlatır-i-lar & damlatır-ma-y- $\varnothing$ & damlatır-ma-y-lar \\
\hline & \multicolumn{4}{|c|}{ doldur- } \\
\hline 1. SS & doldur-i-m & doldur-i-s & doldur-ma-y-m & doldur-ma-y-s \\
\hline 2. SS & doldur-i-sin & doldur-i-sin1z & doldur-ma-y-sin & doldur-ma-y-sin1z \\
\hline \multirow[t]{2}{*}{ 3. Ş } & doldur-i- $\varnothing$ & doldur-i-lar & doldur-ma-y-Ø & doldur-ma-y-lar \\
\hline & \multicolumn{4}{|c|}{ ettır- (<ettir-) } \\
\hline 1. Ş & ettır-i-m & ettır-i-s & ettır-me-y-m & ettır-me-y-s \\
\hline
\end{tabular}




\begin{tabular}{|c|c|c|c|c|}
\hline 2. Ş & ettır-i-sin & ettır-i-sinız & ettır-me-y-sın & ettır-me-y-sinız \\
\hline 3. Ş & ettır-i- $\varnothing$ & ettır-i-lar & ettır-me-y- $\varnothing$ & ettır-me-y-lar \\
\hline & \multicolumn{4}{|c|}{$i c ̧ ı l-(<i c ̧ i l-)$} \\
\hline 1. Ş & içıl-i-m & iç1l-i-s & iç1l-me-y-m & iç1l-me-y-s \\
\hline 2. Ş & içı1l-i-sin & iç1l-i-sınız & içıl-me-y-sın & iç1l-me-y-sinız \\
\hline \multirow[t]{2}{*}{ 3. SS } & iç1l-i-Ø & içıl-i-lar & iç1l-me-y-Ø & içıl-me-y-lar \\
\hline & \multicolumn{4}{|c|}{ ikatır- $(<y$ lkat- $)$} \\
\hline 1. Ş & ikatır-i-m & ikatır-i-s & ikatır-ma-y-m & ikatır-ma-y-s \\
\hline 2. SS & ikatır-i-sin & ikatır-i-sınız & ikatır-ma-y-sın & ikatır-ma-y-sinız \\
\hline \multirow[t]{2}{*}{ 3. SS } & ikatır-i- $\varnothing$ & ikatır-i-lar & ikatır-ma-y-Ø & ikatır-ma-y-lar \\
\hline & \multicolumn{4}{|c|}{ kaşın- } \\
\hline 1. Ş & kaşın-i-m & kaşın-i-s & kaşın-ma-y-m & kaşın-ma-y-s \\
\hline 2. Ş & kaşın-i-sın & kaşın-i-sınız & kaşın-ma-y-sın & kaşın-ma-y-sınız \\
\hline \multirow[t]{2}{*}{ 3. Ş } & kaşın-i- $\varnothing$ & kaşın-i-lar & kaşın-ma-y- $\varnothing$ & kaşın-ma-y-lar \\
\hline & \multicolumn{4}{|c|}{ otur- } \\
\hline 1. SS & otur-i-m & otur-i-s & otur-ma-y-m & otur-ma-y-s \\
\hline 2. SS & otur-i-sin & otur-i-siniz & otur-ma-y-sin & otur-ma-y-sinız \\
\hline \multirow[t]{2}{*}{ 3. SS } & otur-i- $\varnothing$ & otur-i-lar & otur-ma-y-Ø & otur-ma-y-lar \\
\hline & \multicolumn{4}{|c|}{ sardir- } \\
\hline 1. Ş & sardir-i-m & sardır-i-s & sardir-ma-y-m & sardır-ma-y-s \\
\hline
\end{tabular}




\begin{tabular}{|c|c|c|c|c|}
\hline 2. Ş & sardir-i-sin & sardır-i-sınız & sardır-ma-y-sin & sardir-ma-y-sinız \\
\hline 3. Ş & sardir-i- $\varnothing$ & sardır-i-lar & sardır-ma-y- $\varnothing$ & sardır-ma-y-lar \\
\hline & \multicolumn{4}{|c|}{ sevin- $(<$ sevin -$)$} \\
\hline 1. Ş & sevin-i-m & sevin-i-s & sevin-me-y-m & sevin-me-y-s \\
\hline 2. Ş & sevin-i-sin & sevin-i-sinız & sevin-me-y-sin & sevin-me-y-sin1z \\
\hline \multirow[t]{2}{*}{ 3. SS } & sevin-i- $\varnothing$ & sevin-i-lar & sevin-me-y- & sevin-me-y-lar \\
\hline & \multicolumn{4}{|c|}{ sülen- (<söylen-) } \\
\hline 1. Ş & sülen-i-m & sülen-i-s & sülen-me-y-m & sülen-me-y-s \\
\hline 2. SS & sülen-i-sin & sülen-i-sınız & sülen-me-y-sin & sülen-me-y-sinız \\
\hline \multirow[t]{2}{*}{ 3. SS } & sülen-i- $\varnothing$ & sülen-i-lar & sülen-me-y-Ø & sülen-me-y-lar \\
\hline & \multicolumn{4}{|c|}{ taran- } \\
\hline 1. Ş & taran-i-m & $\operatorname{taran}-\mathrm{i}-\mathrm{s}$ & taran-ma-y-m & taran-ma-y-s \\
\hline 2. Ş & $\operatorname{taran}-\mathrm{i}-\mathrm{s} \ln$ & $\operatorname{taran}-\mathrm{i}-\sin 1 \mathrm{z}$ & taran-ma-y-sin & taran-ma-y-siniz \\
\hline \multirow[t]{2}{*}{ 3. Ş } & $\operatorname{taran}-\mathrm{i}-\varnothing$ & taran-i-lar & taran-ma-y- & taran-ma-y-lar \\
\hline & \multicolumn{4}{|c|}{ uçur- } \\
\hline 1. SS & uçur-i-m & uçur-i-s & uçur-ma-y-m & uçur-ma-y-s \\
\hline 2. SS & uçur-i-sin & uçur-i-sınız & uçur-ma-y-sın & uçur-ma-y-sın1z \\
\hline \multirow[t]{2}{*}{ 3. SS } & uçur-i-Ø & uçur-i-lar & uçur-ma-y-Ø & uçur-ma-y-lar \\
\hline & \multicolumn{4}{|c|}{ üdetır- $(<\ddot{o d e t}-)$} \\
\hline 1. Ş & üdetır-i-m & üdetır-i-s & üdetır-me-y-m & üdetır-me-y-s \\
\hline
\end{tabular}




\begin{tabular}{|c|c|c|c|c|}
\hline 2. Ş & üdetır-i-sın & üdetır-i-sınız & üdetır-me-y-sin & üdetır-me-y-sın1z \\
\hline 3. Ş & üdetır-i- $\varnothing$ & üdetır-i-lar & üdetır-me-y- $\varnothing$ & üdetır-me-y-lar \\
\hline & \multicolumn{4}{|c|}{ üldür- (<öldür-) } \\
\hline 1. Ş & üldür-i-m & üldür-i-s & üldür-me-y-m & üldür-me-y-s \\
\hline 2. Ş & üldür-i-sin & üldür-i-sınız & üldür-me-y-sın & üldür-me-y-sinız \\
\hline \multirow[t]{2}{*}{ 3. SS } & üldür-i- $\varnothing$ & üldür-i-lar & üldür-me-y-Ø & üldür-me-y-lar \\
\hline & \multicolumn{4}{|c|}{ uyan- } \\
\hline 1. Ş & uyan-i-m & uyan-i-s & uyan-ma-y-m & uyan-ma-y-s \\
\hline 2. SS & uyan-i-sin & uyan-i-sin1z & uyan-ma-y-sın & uyan-ma-y-siniz \\
\hline \multirow[t]{2}{*}{ 3. SS } & uyan-i-Ø & uyan-i-lar & uyan-ma-y-Ø & uyan-ma-y-lar \\
\hline & \multicolumn{4}{|c|}{ uyandir- } \\
\hline 1. Ş & uyandir-i-m & uyandır-i-s & uyandır-ma-y-m & uyandır-ma-y-s \\
\hline 2. Ş & uyandir-i-sin & uyandir-i-sin1z & uyandir-ma-y-sin & uyandır-ma-y-sinız \\
\hline \multirow[t]{2}{*}{ 3. Ş } & uyandir-i-Ø & uyandir-i-lar & uyandır-ma-y-Ø & uyandır-ma-y-lar \\
\hline & \multicolumn{4}{|c|}{ uyutur- (<uyut-) } \\
\hline 1. SS & uyutur-i-m & uyutur-i-s & uyutur-ma-y-m & uyutur-ma-y-s \\
\hline 2. SS & uyutur-i-sin & uyutur-i-sin1z & uyutur-ma-y-sin & uyutur-ma-y-sin1z \\
\hline \multirow[t]{2}{*}{ 3. SS } & uyutur-i- $\varnothing$ & uyutur-i-lar & uyutur-ma-y- $\varnothing$ & uyutur-ma-y-lar \\
\hline & \multicolumn{4}{|c|}{ yaşat- } \\
\hline 1. Ş & yaşat-i-m & yaşat-i-s & yaşat-ma-y-m & yaşat-ma-y-s \\
\hline
\end{tabular}




\begin{tabular}{|c|l|l|l|l|}
\hline 2. Ş & yaşat-i-sın & yaşat-i-sınız & yaşat-ma-y-sın & yaşat-ma-y-sınız \\
\hline 3. Ş & yaşat-i- $\varnothing$ & yaşat-i-lar & yaşat-ma-y- $\varnothing$ & yaşat-ma-y-lar \\
\hline & \multicolumn{4}{|c|}{ yedır- (<yedir-) } \\
\hline $\mathbf{1 . S}$ & yedır-i-m & yedır-i-s & yedır-me-y-m & yedır-me-y-s \\
\hline 2. Ş & yedır-i-sın & yedır-i-sınız & yedır-me-y-sın & yedır-me-y-sınız \\
\hline 3. Ş & yedır-i- $\varnothing$ & yedır-i-lar & yedır-me-y- $\varnothing$ & yedır-me-y-lar \\
\hline
\end{tabular}

Bir de, "et-“ yardımcı fiiliyle kurulan birleşik fiilere /-i/ varyantı eklenir:

\begin{tabular}{|c|c|c|c|c|}
\hline & \multicolumn{2}{|c|}{ OLUMLULUK } & \multicolumn{2}{|c|}{ OLUMSUZLUK } \\
\hline & TEKLIK & ÇOKLUK & TEKLIK & ÇOKLUK \\
\hline & \multicolumn{4}{|c|}{ afet- $(<$ affet- $)$} \\
\hline 1. Ş & afed-i-m & afed-i-s & afet-me-y-m & afet-me-y-s \\
\hline 2. SS & afed-i-sin & afed-i-sinız & afet-me-y-sin & afet-me-y-sinız \\
\hline \multirow[t]{2}{*}{ 3. SS } & afed-i-Ø & afed-i-lar & afet-me-y-Ø & afet-me-y-lar \\
\hline & \multicolumn{4}{|c|}{ farket- (<fark et-) } \\
\hline 1. SS & farked-i-m & farked-i-s & farket-me-y-m & farket-me-y-s \\
\hline 2. Ş & farked-i-sin & farked-i-sinız & farket-me-y-sin & farket-me-y-sin1z \\
\hline 3. Ş & farked-i- $\varnothing$ & farked-i-lar & farket-me-y-Ø & farket-me-y-lar \\
\hline
\end{tabular}

\section{Geniş Zaman Kipi}

Geniş zaman kipi, Makedonya'nın güney Türk ağılarında çok kullanılmaktadır, ancak Üsküp ağzında neredeyse hiç rastlanmaz. Üsküp'te geniş zaman yerine, şimdiki zaman kipi tercih edilir (Ahmed, 2014: 8). Çok az rastlanılan örnekte de, bu kipin Standart Türkçeden fark1 yok. 
- Böylece, ünlüyle biten fiillere doğrudan doğruda geniş zamanın esas şekli olan /-r/ eki eklenir.

- Ünsüzle biten fiillerde ise, bu ekten önce yardımcı bir geniş ünlü eklenir (/-(A)r/ biçimi).

- Öte yandan, "l” ve "r" ile biten fiillerde, ekten önce yardımcı bir dar ünlü girmektedir (/-(I)r/ biçimi), fakat burada yardımcı ünlü olarak, "i” hariç, diğer üç dar ünlü rastlanır.

- Olumsuz şekillerinde, Standart Türkçedeki gibi, birinci teklik ve çokluk şahısta geniş zaman eki düşer, ikinci teklik ve çokluk ile üçüncü teklik şahıslarda ise /-s/ varyantıyla, üçüncü çokluk şahısta da /-z/ varyantıyla kullanılmaktadır.

\begin{tabular}{|c|c|c|c|c|}
\hline & \multicolumn{2}{|c|}{ OLUMLULUK } & \multicolumn{2}{|c|}{ OLUMSUZLUK } \\
\hline & TEKLİK & ÇOKLUK & TEKLİK & ÇOKLUK \\
\hline & \multicolumn{4}{|c|}{ bil- } \\
\hline 1. Ş & bil-(1)r-1m & bil-(1)r-1Z & bil-me-Ø-m & bil-me-Ø-ys \\
\hline 2. Ş & bil-(1)r-sin & bil-(1)r-sin1z & bil-me-s-sin & bil-me-s-sin1z \\
\hline \multirow[t]{2}{*}{ 3. Ş } & bil-(1)r- $\varnothing$ & bil-(1)r-lar & bil-me-s-Ø & bil-me-z-lar \\
\hline & \multicolumn{4}{|c|}{ bul- } \\
\hline 1. Ş & bul-(u)r-um & bul-(u)r-uz & bul-ma-Ø-m & bul-ma-Ø-ys \\
\hline 2. Ş & bul-(u)r-sin & bul-(u)r-sinız & bul-ma-s-sin & bul-ma-s-sinız \\
\hline \multirow[t]{2}{*}{ 3. Ş } & bul-(u)r-Ø & bul-(u)r-lar & bul-ma-s- $\varnothing$ & bul-ma-z-lar \\
\hline & \multicolumn{4}{|c|}{ gür- (<gör-) } \\
\hline 1. $S$ & gür-(ü)r-1m & gür-(ü)r-1Z & gür-me-Ø-m & gür-me-Ø-ys \\
\hline 2. $S$ & gür-(ü)r-sin & gür-(ü)r-sınız & gür-me-s-sın & gür-me-s-sınız \\
\hline 3. Ş & gür-(ü)r-Ø & gür-(ü)r-lar & gür-me-s-Ø & gür-me-z-lar \\
\hline
\end{tabular}




\begin{tabular}{|c|c|c|c|c|}
\hline & \multicolumn{4}{|c|}{$i k a-(<y \imath k a-)$} \\
\hline 1. SS & ika-r-1m & ika-r-1z & ika-ma-Ø-m & ika-ma-Ø-ys \\
\hline 2. SS & ika-r-sın & ika-r-sınız & ika-ma-s-sın & ika-ma-s-sınız \\
\hline \multirow[t]{2}{*}{ 3. Ş } & ika-r-Ø & ika-r-lar & ika-ma-s- & ika-ma-z-lar \\
\hline & \multicolumn{4}{|c|}{ koş- } \\
\hline 1. SS & koş-(a)r-1m & koş-(a)r-1z & koş-ma-Ø-m & koş-ma-Ø-ys \\
\hline 2. SS & koş-(a)r-sin & koş-(a)r-sınız & koş-ma-s-sin & koş-ma-s-sin1z \\
\hline \multirow[t]{2}{*}{ 3. Ş } & koş-(a)r- Ø & koş-(a)r-lar & koş-ma-s- $\varnothing$ & koş-ma-z-lar \\
\hline & \multicolumn{4}{|c|}{ oku- } \\
\hline 1. Ş & oku-r-um & oku-r-uz & oku-ma-Ø-m & oku-ma-Ø-ys \\
\hline 2. SS & oku-r-sin & oku-r-sinız & oku-ma-s-sin & oku-ma-s-sin1z \\
\hline \multirow[t]{2}{*}{ 3. SS } & oku-r-Ø & oku-r-lar & oku-ma-s- $\varnothing$ & oku-ma-z-lar \\
\hline & \multicolumn{4}{|c|}{ sev- } \\
\hline 1. Ş & sev-(e)r-1m & sev-(e)r-1z & sev-me-Ø-m & sev-me-Ø-ys \\
\hline 2. SS & sev-(e)r-sin & sev-(e)r-siniz & sev-me-s-sin & sev-me-s-sinız \\
\hline 3. SS & sev-(e)r-Ø & sev-(e)r-lar & sev-me-s- $\varnothing$ & sev-me-z-lar \\
\hline
\end{tabular}

\section{Gelecek Zaman Kipi}

Üsküp Türk ağzında bu kipin varyantları şöyledir:

- Üçüncü teklik ve çokluk şahısta asıl olan /-AcAk/ biçimleri;

- Birinci teklik ile ikinci teklik ve çokluk şahıslarında /-AcA/ biçimleri;

- Birinci çokluk şahısta /-Ac/ biçimleriyle rastlanmaktadır. 


\begin{tabular}{|c|c|c|c|c|}
\hline & \multicolumn{2}{|c|}{ OLUMLULUK } & \multicolumn{2}{|c|}{ OLUMSUZLUK } \\
\hline & TEKLIK & ÇOKLUK & TEKLIKK & ÇOKLUK \\
\hline & \multicolumn{4}{|c|}{ gel- } \\
\hline 1. Ş & gel-ece-m & gel-ec-iz & gel-me-(y)ece-m & gel-me-(y)ec-iz \\
\hline 2. SS & gel-ece-n & gel-ece-nız & gel-me-(y)ece-n & gel-me-(y)ece-n1z \\
\hline \multirow[t]{2}{*}{ 3. SS } & gel-ecek- $\varnothing$ & gel-ecek-lar & gel-me-(y)ecek-lar & gel-me-(y)ecek-lar \\
\hline & \multicolumn{4}{|c|}{$i k a-(<y l k a-)$} \\
\hline 1. Ş & ika-(y)aca-m & ika-(y)ac-iz & ika-ma-(y)aca-m & ika-ma-(y)ac-iz \\
\hline 2. Ş & ika-(y)aca-n & ika-(y)aca-nız & ika-ma-(y)aca-n & ika-ma-(y)aca-nız \\
\hline \multirow[t]{2}{*}{ 3. Ş } & ika-(y)acak-Ø & ika-(y)acak-lar & ika-ma-(y)acak-lar & ika-ma-(y)acak-lar \\
\hline & \multicolumn{4}{|c|}{ ver- } \\
\hline 1. Ş & ver-ece-m & ver-ec-iz & ver-me-(y)ece-m & ver-me-(y)ec-iz \\
\hline 2. SS & ver-ece-n & ver-ece-nız & ver-me-(y)ece-n & ver-me-(y)ece-nız \\
\hline \multirow[t]{2}{*}{ 3. SS } & ver-ecek- $\varnothing$ & ver-ecek-lar & ver-me-(y)ecek-lar & ver-me-(y)ecek-lar \\
\hline & \multicolumn{4}{|c|}{ yap- } \\
\hline 1. Ş & yap-aca-m & yap-ac-iz & yap-ma-(y)aca-m & yap-ma-(y)ac-iz \\
\hline 2. SS & yap-aca-n & yap-aca-n1z & yap-ma-(y)aca-n & yap-ma-(y)aca-nız \\
\hline 3. Ş & yap-acak- Ø & yap-acak-lar & yap-ma-(y)acak-lar & yap-ma-(y)acak-lar \\
\hline
\end{tabular}

$\mathrm{Bu}$ arada, üçüncü çokluk şahıs eki /-lar/'ın kullanımından genelde kaçınıldığını söylemekte fayda vardır. Şahıs eki yerine, genelde fiilden önce zamir kullanılır:

Onlar gelecek.

Karilar adamlari odaya almayacak. 


\section{Dilek Kipleri}

\section{İstek Kipi}

Üsküp ağzında, istek kipi emir kipiyle karışmıştır. Bu karıştırmanın hem ek olarak, hem de anlam olarak çoğu zaman birbirine girdiğini vurgulamak gerekir.

İstek kipi, birinci ve ikinci teklik ve çokluk şahıslarda /-A/ ekiyle görülür.

Üçüncü teklik ve çokluk şahıslarda ise, istek kipinin eki yoktur ve biçim olarak emir kipiyle aynıdır.

\begin{tabular}{|c|c|c|c|c|}
\hline & \multicolumn{2}{|c|}{ OLUMLULUK } & \multicolumn{2}{|c|}{ OLUMSUZLUK } \\
\hline & TEKLIKK & ÇOKLUK & TEKLİK & ÇOKLUK \\
\hline & \multicolumn{4}{|c|}{ gel- } \\
\hline 1. Ş & gel-e-m & gel-e-lim & gel-me-(y)e-m & gel-me-(y)e-lim \\
\hline 2. Ş & gel-e-sin & gel-e-sin1z & gel-me-(y)e-sin & gel-me-(y)e-sinız \\
\hline \multirow[t]{2}{*}{ 3. SS } & gel-Ø-sin & gel-Ø-sinlar & gel-me-Ø-sin & gel-me-Ø-sınlar \\
\hline & \multicolumn{4}{|c|}{ oku- } \\
\hline 1. Ş & oku-(y)a-m & oku-(y)a-lim & oku-ma-(y)a-m & oku-ma-(y)a-lım \\
\hline 2. Ş & oku-(y)a-sin & oku-(y)a-sin1z & oku-ma-(y)a-sin & oku-ma-(y)a-siniz \\
\hline \multirow[t]{2}{*}{ 3. SS } & oku-Ø-sun & oku-Ø-sunlar & oku-ma-sın & oku-ma-Ø-sinlar \\
\hline & \multicolumn{4}{|c|}{ brak- $(<$ birak-) } \\
\hline 1. Ş & brag-a-m & brag-a-lim & brak-ma-(y)a-m & brak-ma-(y)a-lım \\
\hline 2. Ş & brag-a-sin & brag-a-sinız & brak-ma-(y)a-sin & $\begin{array}{l}\text { brak-ma-(y)a- } \\
\text { siniz }\end{array}$ \\
\hline 3. Ş & brak-Ø-sin & brak-Ø-sinlar & brak-ma-Ø-sin & brak-ma-Ø-sinlar \\
\hline
\end{tabular}

Emir Kipi 
Standart Türkçeden farksız olarak, Üsküp ağzında da emir kipinin biçimleri aynıdır. Diğer sözlerle, birinci teklik ve çokluk şahıslarda, /-A/ istek kip eki kullanılır, öteki şahıslarda ise emir kipi şahıs ekleriyle karışmıştır.

\begin{tabular}{|c|c|c|c|c|}
\hline & \multicolumn{2}{|c|}{ OLUMLULUK } & \multicolumn{2}{|c|}{ OLUMSUZLUK } \\
\hline & TEKLIK & ÇOKLUK & TEKLIK & ÇOKLUK \\
\hline & \multicolumn{4}{|c|}{ gel- } \\
\hline 1. Ş & gel-e-m & gel-e-lım & gel-me-(y)e-m & gel-me-(y)e-lım \\
\hline 2. Ş & gel-Ø-Ø & gel- $Ø$-1n & gel-me-Ø-Ø & gel-me-Ø-(y)1n \\
\hline \multirow[t]{2}{*}{ 3. Ş } & gel-Ø-sin & gel-Ø-sinlar & gel-me-Ø-sin & gel-me-Ø-sinlar \\
\hline & \multicolumn{4}{|c|}{ oku- } \\
\hline 1.Ş & oku-(y)a-m & oku-(y)a-lım & oku-ma-(y)a-m & oku-ma-(y)a-lım \\
\hline 2. Ş & oku-Ø-Ø & oku-Ø-(y)un & oku-ma-Ø-Ø & oku-ma-Ø-(y)1n \\
\hline \multirow[t]{2}{*}{ 3. Ş } & oku-Ø-sun & oku-Ø-sunlar & oku-ma-Ø-sin & oku-ma-Ø-sinlar \\
\hline & \multicolumn{4}{|c|}{ otur- } \\
\hline 1. Ş & otur-a-m & otur-a-lim & otur-ma-(y)a-m & otur-ma-(y)a-lim \\
\hline 2. Ş & otur- Ø-Ø & otur-Ø-un & otur-ma-Ø-Ø & otur-ma-Ø-(y)in \\
\hline \multirow[t]{2}{*}{ 3. Ş } & otur-Ø-sun & otur-Ø-sunlar & otur-ma-Ø-sin & otur-ma-Ø-sinlar \\
\hline & \multicolumn{4}{|c|}{ ver- } \\
\hline 1. Ş & ver-e-m & ver-e-lım & ver-me-(y)e-m & ver-me-(y)e-lim \\
\hline 2. SS & ver-Ø-Ø & ver-Ø-1n & ver-me-Ø-Ø & ver-me-Ø-(y)1n \\
\hline 3. Ş & ver-Ø-sin & ver-Ø-sinlar & ver-me-Ø-sin & ver-me-Ø-sinlar \\
\hline
\end{tabular}

\section{Gereklilik Kipi}


Morfolojik yönden (ek olarak) gereklilik kipi Üsküp Türk ağzında yoktur, ancak bu anlam leksik yapıyla elde edilir. Yapılışı şöyle:

- Olumlulukta, fiilin istek kipli çekiminden önce "lâzım” kelimesi getirilir.

- Olumsuzlukta ise, fiilin istek kipli çekiminden önce "lâzım" kelimesi ve "dil" (<değil) olumsuzluk edatı girer ("lâzım dil”" < lâzım değil).

\begin{tabular}{|c|c|c|c|c|}
\hline & \multicolumn{2}{|c|}{ OLUMLULUK } & \multicolumn{2}{|c|}{ OLUMSUZLUK } \\
\hline & TEKLİK & ÇOKLUK & TEKLİK & ÇOKLUK \\
\hline & \multicolumn{4}{|c|}{ gel- } \\
\hline 1. Ş & lâzım gel-e-m & lâzım gel-e-lım & lâzım dil gel-e-m & lâzım dil gel-e-lım \\
\hline 2. SS & lâzım gel-e-sın & lâzım gel-e-sınız & lâzım dil gel-e-sın & lâzım dil gel-e-sınız \\
\hline \multirow[t]{2}{*}{ 3. Ş } & lâzım gel-Ø-sın & lâzım gel-Ø-sınlar & lâzım dil gel-Ø-sın & lâzım dil gel-Ø-sınlar \\
\hline & \multicolumn{4}{|c|}{ seç- } \\
\hline 1. Ş & lazım seç-e-m & lâzım seç-e-lım & lazım dil seç-e-m & lâzım dil seç-e-lım \\
\hline 2. SS & lazım seç-e-sın & lâzım seç-e-sınız & lazım dil seç-e-sın & lâzım dil seç-e-sınız \\
\hline 3. Ş & lazım seç-sın & lâzım seç-Ø-sınlar & lazım dil seç-sın & lâzım dil seç-Ø-sınlar \\
\hline
\end{tabular}

\section{Dilek-Şart Kipi}

Hem dilek hem şart görevinde kullanılan bu kip, basit kipli fiillerde ünlü uyumlarına bakmaksızın, sadece /-sa/ varyantıyla kullanılır.

\begin{tabular}{|c|l|l|l|l|}
\hline & \multicolumn{2}{|c|}{ OLUMLULUK } & \multicolumn{2}{c|}{ OLUMSUZLUK } \\
\hline & \multicolumn{1}{|c|}{ TEKLIK } & \multicolumn{1}{|c|}{ ÇOKLUK } & TEKLIK & ÇOKLUK \\
\hline & \multicolumn{3}{|c|}{ bak- } & bak-ma-sa-k \\
\hline $\mathbf{1 . S}$ & bak-sa-m & bak-sa-k & bak-ma-sa-m & bak-ma-sa-nız \\
\hline 2. Ş & bak-sa-n & bak-sa-nız & bak-ma-sa-n & \\
\hline
\end{tabular}




\begin{tabular}{|c|c|c|c|c|}
\hline 3. SS & bak-sa- $\varnothing$ & bak-sa-lar & bak-ma-sa- & bak-ma-sa-lar \\
\hline & \multicolumn{4}{|c|}{ gel- } \\
\hline 1. Ş & gel-sa-m & gel-sa-k & gel-me-sa-m & gel-me-sa-k \\
\hline 2. SS & gel-sa-n & gel-sa-n1z & gel-me-sa-n & gel-me-sa-nız \\
\hline \multirow[t]{2}{*}{ 3. SS } & gel-sa-Ø & gel-sa-lar & gel-me-sa- $\varnothing$ & gel-me-sa-lar \\
\hline & \multicolumn{4}{|c|}{$o k u-$} \\
\hline 1. Ş & oku-sa-m & oku-sa-k & oku-ma-sa-m & oku-ma-sa-k \\
\hline 2. SS & oku-sa-n & oku-sa-niz & oku-ma-sa-n & oku-ma-sa-nız \\
\hline \multirow[t]{2}{*}{ 3. SS } & oku-sa- $\varnothing$ & oku-sa-lar & oku-ma-sa- $\varnothing$ & oku-ma-sa-lar \\
\hline & \multicolumn{4}{|c|}{ ol- } \\
\hline 1. Ş & ol-sa-m & ol-sa-k & ol-ma-sa-m & ol-ma-sa-k \\
\hline 2. Ş & ol-sa-n & ol-sa-n1z & ol-ma-sa-n & ol-ma-sa-n1z \\
\hline \multirow[t]{2}{*}{ 3. SS } & ol-sa-Ø & ol-sa-lar & ol-ma-sa-Ø & ol-ma-sa-lar \\
\hline & \multicolumn{4}{|c|}{$\ddot{u}$ şü- } \\
\hline 1. Ş & üşü-sa-m & üşü-sa-k & üşü-me-sa-m & üşü-me-sa-k \\
\hline 2. SS & üşü-sa-n & üşü-sa-nız & üşü-me-sa-n & üşü-me-sa-n1z \\
\hline \multirow[t]{2}{*}{ 3. Ş } & üşü-sa-Ø & üşü-sa-lar & üşü-me-sa-Ø & üşü-me-sa-lar \\
\hline & \multicolumn{4}{|c|}{ ver- } \\
\hline 1. Ş & ver-sa-m & ver-sa-k & ver-me-sa-m & ver-me-sa-k \\
\hline 2. SS & ver-sa-n & ver-sa-n1z & ver-me-sa-n & ver-me-sa-nız \\
\hline
\end{tabular}




\begin{tabular}{|l|l|l|l|l|}
\hline 3. Ş & ver-sa- $\varnothing$ & ver-sa-lar & ver-me-sa- $\varnothing$ & ver-me-sa-lar \\
\hline
\end{tabular}

$\mathrm{Bu}$ eki, şart birleşik kipli fiillerde kullanıldığında ise, sadece /-se/ varyantıyla görmek mümkündür:

\begin{tabular}{|c|c|c|c|c|}
\hline & \multicolumn{2}{|c|}{ OLUMLULUK } & \multicolumn{2}{|c|}{ OLUMSUZLUK } \\
\hline & TEKLIK & ÇOKLUK & TEKLIK & ÇOKLUK \\
\hline & \multicolumn{4}{|c|}{$a l-$} \\
\hline 1. Ş & al-di-(y)se-m & al-di-(y)se-k & al-ma-di-(y)se-m & al-ma-di-(y)se-k \\
\hline 2. Ş & al-di-(y)se-n & al-di-(y)se-n1z & al-ma-di-(y)se-n & al-ma-di-(y)se-nız \\
\hline \multirow[t]{2}{*}{ 3. SS } & al-di-(y)se- $\emptyset$ & al-di-(y)se-lar & al-ma-di-(y)se- $\varnothing$ & al-ma-di-(y)se-lar \\
\hline & \multicolumn{4}{|c|}{ 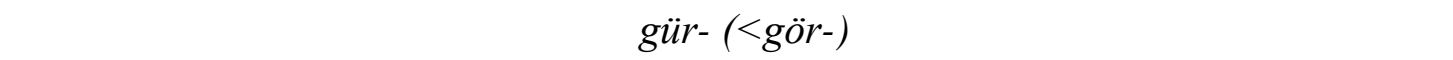 } \\
\hline 1. S S & gür-di-(y)se-m & gür-di-(y)se-k & gür-me-di-(y)se-m & gür-me-di-(y)se-k \\
\hline 2. Ş & gür-di-(y)se-n & gür-di-(y)se-nız & gür-me-di-(y)se-n & gür-me-di-(y)se-nız \\
\hline \multirow[t]{2}{*}{ 3. Ş } & gür-di-(y)se- $\varnothing$ & gür-di-(y)se-lar & gür-me-di-(y)se- $\varnothing$ & gür-me-di-(y)se-lar \\
\hline & \multicolumn{4}{|c|}{ koş- } \\
\hline 1. Ş & koş-ti-(y)se-m & koş-ti-(y)se-k & koş-ma-di-(y)se-m & koş-ma-di-(y)se-k \\
\hline 2. SS & koş-ti-(y)se-n & koş-ti-(y)se-nız & koş-ma-di-(y)se-n & koş-ma-di-(y)se-nız \\
\hline 3. Ş & koş-ti-(y)se- $\varnothing$ & koş-ti-(y)se-lar & koş-ma-di-(y)se- $\varnothing$ & koş-ma-di-(y)se-lar \\
\hline
\end{tabular}

Sonuç

Bu bildiride, Üsküp Türk ağzındaki bildirme ve dilek kipleri ele alındı.

Bildirme kiplerinden dördü (belirsiz ve belirli geçmiş zaman, şimdiki zaman ve geniş zaman) sık, biri ise (geniş zaman) neredeyse hiç kullanılmaz.

Belirsiz geçmiş zaman eki her durumda sadece bir tek, /-miş/ varyantıyla kullanılmaktadır. 
Belirli geçmiş zaman kip eki üçüncü teklik ve çokluk şahısta sadece /-di/ ve /-ti/ varyantıyla, birinci ve ikinci teklik ve çokluk şahısta ise bunların dışında geriye kalan tüm diğer altı varyantıyla kullanılır.

Birleşik kipli durumlarda ise, kendisinden sonra şart birleşik kipi gelir ise, ünsüz uyumuna göre tekrar sadece/-di/ ve /-ti/ varyantlarına rastlanır.

Üsküp Türk ağzının asıl karakteristik özelliği şimdiki zaman kipidir. Bu kip, ünlüyle biten tüm fiillerde sadece /-y/ varyantıyla kullanılır. Ünsüzle biten fiil köklerine iki varyantlı /-Ay/ biçimiyle eklenir. Bundan farklı olarak, "l" ve "r" ünsüzleriyle biten fiillerde /-i/ varyantıyla rastlanır. Bu /-i/ varyantı, fiil çatı ve üst üste gelen fiil çatı eklerinden sonra da kullanılan tek şimdiki zaman biçimidir. Dahası, "et-" yardımcı fiiliyle kurulan birleşik fiillerde de bu biçim kullanılır.

Geniş zaman kipi, Makedonya'nın diğer bazı kuzey ağızlarında da olduğu gibi, neredeyse hiç kullanılmaz. Genelde geniş zaman yerine, şimdiki zaman kipi tercih edilir. Geniş zaman kip eki, Üsküp ağzında da Standart Türkçeden farksız bir şekilde kullanılır: ünlüyle biten fiillere esas olan /-r/ şekliyle, ünsüzle biten fiillerde ekten önce geniş ünlü eklenerek, "l” ve "r" ünsüzüyle biten fiilerde ise, kendisinden önce araya dar bir ünlü girerek kullanılır, ancak bu dar ünlülerden, “i” ünlüsü hariç, diğer üçü kullanılmaktadır. Olumsuzlukta, birinci teklik ve çokluk şahısta ek düşer, ikinci teklik ve çokluk ile üçüncü teklikte /-s/, üçüncü çoklukta ise /-z/ varyantı kullanılır.

Gelecek zaman kipi sadece üçüncü şahıs teklik ve çoklukta asıl iki varyantlı /-AcAk/ biçimiyle kullanılır. Birinci teklik ve ikinci teklik ve çokluk şahıslarında iki varyantlı/-AcA/ biçimiyle, birinci çokluk şahısta ise sadece iki varyantlı/-Ac/ biçimiyle kullanılmaktadır.

Dilek kiplerine gelince, istek kipi ve emir kipi bazı özellikleriyle birbirine benzemekte, gereklilik kip eki ise kesinlikle yoktur.

İstek kipi birinci ve ikinci teklik ve çoklukta /-A/ varyantlarıyla kullanılır. Üçüncü teklik ve çoklukta ise bu kipin eki yok ve biçim olarak emir kipine benzemektedir.

Emir kipinde ise, birinci teklik ve çokluk şahısta emir anlamında kullanılan istek kipinin /-A/ şekli kullanılır. Öteki şahıslarda ise Standart Türkçeden farkı yoktur.

Gereklilik kipi bu ağızda yoktur, ancak bu anlam, fiilin istek kipi şekli ve fiilden önce "lâzım" kelimesi gelerek elde edilir. Olumsuzluklarda ise fiilden önce "lâzım dil" (<lâzim değil) biçimi eklenerek kullanılır.

Dilek-şart kipi her zaman bir tek /-sa/ varyantıyla görülür. Bu ek, birleşik kiplerde şart görevinde kullanılmışsa, o zaman ise sadece /-se/ varyantı kullanılmaktadır.

\section{Kaynakça}


Ahmed, O. (2007). Makedonya'nın Ohri-Prespa Yöresinde Konuşulan Türk Ağızlarında Eklerin Varyantları. I. Uluslararası Türk Dünyası Kültür Kurultayı - 09-15 Nisan 2006 - Çeşme-İzmir - Bildiri Kitabı Cilt I. İzmir: Ege Üniversitesi Türk Dünyası Araştırmaları Enstitüsü. s. 31-42.

Ahmed, O. (2012a). Makedonya Türk Ağızlarında İki Sesin Durumu Üzerine: “Ö” Ünlüsü ve “H” Ünsüzü. Uluslararası Türkçe Edebiyat Kültür Eğitim Dergisi, 1(2). s. 15-26.

Ahmed, O. (2012b). Pulevski'nin Sözlüklerinden Hareketle XIX. Yüzyıl Makedonya Türkçesinin Bazı Ses Özellikleri. VII. Uluslararası Türk Dili Kurultayı, 24-28 Eylül 2012, Ankara. (Basılmamış bildiri).

Ahmed, O. (2014). Makedonya Türk Ağızlarında Şimdiki ve Geniş Zamanın Bugünkü Morfolojik Durumu, Idil, 3(4), s. 1-11.

Friedman, V. (1982). Balkanology and Turcology: West Rumelian Turkish in Yugoslavia as Reflected in Prescriptive Grammar. Studies in Slavic and General Linguistics, Vol. 2. Amsterdam: Rodopi, 1982, pp. 1-77.

Hazai, G. (1964). Rumeli Ağızları Tarihinin İki Kaynağı Üzerine. Türk Dili Araştırmaları Yıllığı Belleten, 1963, 117-120.

Kowalski, T. (1919). Zagadki ludowe tureckie (Enigmes populaires turques). Prace Komisji Oriental Istyczny Polskiej Akademii Umiejetnosci, No. I, Krakow.

Kowalski, T. (1926). Osmanisch-türkische Volkslieder aus Mazedonien. WZKM, XXXIII. 166-231.

Kúnos, Ignácz. (1918). Rumelisch-Türkische Sprichwörter. KSz VII(1). s. 66-83.

Németh, G. (1956). Zur Einleitung der türkischen Mundarten Bulgariens. Sofia: Bulgarische Akademie der Wissenschaften.

Németh, G. (1983). Bulgaristan Türk Ağılarının Sınıflandırılması Üzerine. Türk Dili Araştırmaları Yıllı̆̆ Belleten, 1980-1981. s. 113-167.

Државен завод за статистика. (2005, мај). Попис на населението, домаќинствата и становите во Република Македонија, 2002 (Дефинитивни податоци, книга ХІІІ), Скопје.

Пулевски, Ђ. М. (1873). Речник от четири јазика: I. српско-албански - II. арбанскиарнаутски - III. турски - IV. грчки. Београд.

Пуљевски, Ђ. М. (1875). Речник от три језика: С. Македонски - Арбански - Турски (Lugat Üç Lisaniden: Misniymance - Arnaudçes ve S. Makedonluces) - књига II. Београд: Државна штампарија. 